\title{
The Role of Carrier in Dry Powder Inhaler
}

\author{
Hamed Hamishehkar, Yahya Rahimpour and Yousef Javadzadeh
}

Additional information is available at the end of the chapter

http://dx.doi.org/10.5772/51209

\section{Introduction}

Increasing prevalence of pulmonary diseases with high mortality and morbidity such as chronic obstructive pulmonary disease (COPD), asthma, cystic fibrosis, infectious diseases, tuberculosis and lung cancer, makes pulmonary drug delivery as a non-invasive and attractive approach for the local drug administration and treatment of these pathologies (Marianecci et al., 2011). In this case, lower dosages than by the oral route can be used with comparable effectiveness which will reduce unwanted side effects (Timsina et al., 1994).The lung also provides a non-invasive route of delivery for the systemic circulation, due to its unique characteristics such as large surface area, thin epithelial barrier and high blood flow. Lack of first pass metabolism and less enzymatic activity make pulmonary delivery as an ideal administration route for extensively degraded drugs following oral delivery and for macromolecules, such as proteins and peptides, respectively(Hamishehkar et al., 2010; Rytting et al., 2008; Sakagami, 2006). Following approving the first inhaled therapeutic macromolecule for systemic delivery, human insulin (Exubera ${ }^{\mathrm{TM}}$ ) by the Food and Drug Administration (FDA) and the European Agency for the Evaluation of Medicinal Products in 2006, the scientific community look for other candidates that would benefit from pulmonary delivery for systemic action (Patton et al., 2004; Furness, 2005). In contrast to injection therapy, inhalation therapy is not associated with pain and this should increase patient comfort and compliance, causing improved treatment outcome (Laube, 2005). Drug deposition in the lung is mainly controlled by its aerodynamic diameter (Wolff et al., 1993). Particles larger than $5 \mu \mathrm{m}$ are mostly trapped by oropharyngeal deposition and incapable of reaching the lungs while smaller than $1 \mu \mathrm{m}$ are mostly exhaled without deposition (Sakagami, 2006). Particles with aerodynamic diameters between 1 and $5 \mu \mathrm{m}$ are expected to efficiently deposit in the lung periphery (Heyder et al., 1986). The effective inhalation performance of dry-powder products is dependent on the drug formulation and the inhaler device. Dry powder formulations are usually prepared by mixing the micronized drug particles with larger carrier particles. The aerosolization efficiency of a powder is highly dependent on the carrier characteristics, such as particle size distribution, shape and surface 
properties. The main objective in the inhalation field is to achieve reproducible, high pulmonary deposition. This could be achieved by successful carrier selection and careful process optimization (Pilcer et al., 2012). Therefore, the purpose of this chapter is to review the used carriers in inhalable formulations, their production and the impact of the physicochemical properties of carriers on carrier-drug dispersion is discussed in detail. This chapter offers a perspective on current reported studies to modify carrier for its better performance. Several methodologies have been discussed.

\section{Dry powder inhalers}

Pressurized metered-dose inhaler (MDI), nebulizer and dry powder inhaler (DPI) are main delivery systems in pulmonary delivery (Timsina et al., 1994). Among these, DPI appears to be the most promising for future use (Todo et al., 2001).They are propellant-free, portable, easy to operate and low-cost devices with improved stability of the formulation as a result of the dry state(Carpenter et al., 1997; Prime et al., 1997).Spinhaler®, the first dry powder inhaler, came into the market in 1970 and since then a new are started in the subject of pulmonary drug delivery. Dry powder inhalers and dry powder inhalation technology became the second most frequently used inhalation devices for pulmonary drug administration after Montreal Protocol in 1987 in limitation of using CFC in products. Dry powder inhalers have even become the first choice of inhalation devices in European countries (Marriott et al., 2012).They are a widely accepted inhaled delivery dosage form where they are currently used by an estimated $40 \%$ of patients to treat asthma and chronic obstructive pulmonary disease (Atkins, 2005). Using the DPI system, respiratory delivery of potent drugs such as insulin (Edwards et al., 1997), antibiotics (Geller et al., 2007; Hickey et al., 2006), drugs for neurological disorders like Parkinson's disease(Stoessl, 2008), antituberculosis (Anon, 2008), antihypertensive nifedipine( Plumley et al., 2009), anticoagulant heparin (Rawat et al., 2008),drugs for sexual dysfunction (Cheatham et al., 2006), opioids and fentanyl for cancer pain (Farr et al., 2006; Kleinstreuer et al., 2008; Fleischer et al., 2005) and delivery of atropine sulphate nanoparticle as an antidote for organophosphorus poisoning with better bioavailability (Ali et al., 2009) have been studied. DPI formulations of measles vaccine (LiCalsi et al., 2001), mucosal vaccination for influenza virus (Edwards et al., 2005), have all been studied with considerable achievement. DPIs have to overcome various physical difficulties for effective drug delivery either local or systemic purposes (Prime et al., 1997). First, small size of inhalable particles subjected them to forces of agglomeration and cohesion, resulting in poor flow and non-uniform dispersion (Crowder et al., 2002).

\section{The role of carrier on DPI performance}

DPI is generally formulated as a powder mixture of coarse carrier particles and micronized drug particles with aerodynamic particle diameters of 1-5 $\mu$ m (Iida et al., 2003). Carrier particles are used to improve drug particle flowability, thus improving dosing accuracy and minimizing the dose variability observed with drug formulations alone while making them easier to handle during manufacturing operations (Timsina et al., 1994; Schiavone et al., 2004). With the use of carrier particles, drug particles are emitted from capsules and devices 
more readily, hence, the inhalation efficiency increases (Iida et al., 2001). Moreover, usually no more than a few milligrammes of a drug needs to be delivered (e.g., between $20 \mu \mathrm{g}$ and $500 \mu \mathrm{g}$ of corticosteroids for asthma therapy), and thus carrier provides bulk, which improves the handling, dispensing, and metering of the drug (Pilcer et al., 2012). The presence of the carrier material is the taste/sensation on inhaling, which can assure the patient that a dose has been taken (Prime et al., 1997).Consequently, the carrier forms an important component of the formulation and any change in the physico-chemical properties of the carrier particles has the potential to alter the drug deposition profile (Zeng et al., 2000). Therefore, the design of the carrier particle is important for the development of dry powder inhalations (Hamishehkar et al., 2010). Carrier particles should have several characteristics such as physico-chemical stability, biocompatibility and biodegradability, compatible with the drug substance and must be inert, available and economical. During insufflation, the drug particles are detached from the surface of the carrier particles by the energy of the inspired air flow that overcomes the adhesion forces between drug and carrier. The larger carrier particles impact in the upper airways, while the small drug particles go through the lower parts of lungs (Pilcer et al., 2012). Unsatisfactory detachment of drug from the carrier due to strong inter-particulate forces may be one of the main reasons of inefficient drug delivery encountered with most DPIs (Zeng et al., 2000; Zhou et al., 2011). Therefore, in the best case, the adjusted balance between adhesive and cohesive forces provides enough adhesion between drug and carrier to produce a stable formulation (homogeneous mixture with no powder segregation and proper content uniformity) yet allows for easy separation during inhalation. Consequently, it has been stated that the efficiency of a DPI formulation is extremely dependent on the carrier characteristics and the selection of carrier is a crucial determinant of the overall DPI performance (Pilcer et al., 2012). Obviously, the effect of the carrier material on DPI formulation should be carefully evaluated. The range of materials which can be proposed to be as carriers in inhaled products are restricted for toxicological reasons. Lactose and other sugars have been studied and used, therefore modifications to these materials may allow further formulation optimization (Prime et al., 1997).

\section{Inhaler testing equipments}

Cascade impactors operate on the base of inertial impaction. Each stage of the impactor contains a single or series of nozzles or jets through which the sample laden air is drawn directing any airborne particles towards the surface of the collection plate for that particular stage. Whether a particular particle impacts on that stage is dependent on its aerodynamic diameter. Particles having sufficient inertia will impact on that particular stage collection plate whilst smaller particles with insufficient inertia will remain entrained in the air stream and pass to the next stage where the process is repeated. The stages are normally assembled in a stack in order of decreasing particle size. As the jets get smaller, the air velocity increases and finer particles are collected. Any remaining particles are collected on an after filter (or by a -Micro-Orifice Collector). The term 'Impactor' is generally used for an instrument where the particles 'impact' on a dry impaction plate or cup. If the collection surface is liquid, as in the case of the Multi-Stage Liquid Impinger (MSLI), then the term 
'impinger' is used. The general principles of inertial impaction apply to both 'impactors' and 'impingers'. The US and European Pharmacopoeia list no less than five different cascade impactors/impingers suitable for the aerodynamic assessment of fine particles. However, only the Andersen Cascade Impactor (ACI), the Next Generation Impactor (NGI) and the Multi-Stage Liquid Impinger (MSLI) appear in both pharmacopoeia. In research applications, in vitro/in vivo correlation and bioequivalence may be important and so detailed particle size data may be required. In routine quality control, where the concern is batch-to-batch variation a coarser test may be acceptable. The Glass Twin Impinger, for example has been retained as Apparatus A in the European Pharmacopoeia, because of its value as a simple and inexpensive quality control tool. In general however, it is accepted that an Impactor/impinger should have a minimum of five stages and preferably more, if it is to provide detailed particle size distribution data. The aerodynamic particle size distribution of the drug leaving an inhaler device can define the manner in which an aerosol deposits in the respiratory tract during inhalation. This characteristic of the aerosol is often used in judging inhaler performance and is particularly relevant in the development of inhalation formulations during research, production, quality assurance and equivalency testing. The results of characterizations using cascade impaction techniques are additionally used for the determination of fine particle fraction or fine particle dose which may be correlated to the dose or fraction of the drug that penetrates to the lung during inhalation by a patient. Dry Powder Inhaler (DPI) testing could require added options for preventing stage overloading and necessary to achieve the specified pressure drop through the device. Upper stage mass overloading can be prevented with the addition of a high capacity preseparator or pre-collector. The feature traps non-inhalable aerosols. To achieve the proper pressure drop of $4 \mathrm{kPa}(40.8 \mathrm{~cm}$ water) in the inhaler, a higher vacuum flow rate at 60 or $90 \mathrm{~L} /$ minute may be needed.Impactors/impingers are specifically designed to meet the highest criteria laid down in the various Pharmacopoeia (e.g. United States Pharmacopeia Chapter <601>; European Pharmacopoeia Chapter 29.9.18 for characterizing aerosol clouds emitted by inhalers). By analyzing the drug deposited on the individual stages and the final filter, the Fine Particle Fraction (FPF), the Fine Particle Dose (FPD), the Mass Median Aerodynamic Diameter (MMAD) and Geometric Standard Deviation (GSD) can all be calculated (The Copley Scientific Limited, 2010).

\section{Expressions used to define drug lung deposition}

The American and European pharmacopoeias have explained methods based on inertial impaction to assess the in vitro inhalation performance of formulations by determination of the fine particles (Pilcer et al., 2012).

\subsection{Fine Particle Dose (FPD) and fine particle fraction (FPF)}

The aerodynamic evaluation methods of fine particles permit the determination of the fineparticle dose (FPD), which corresponds to the mass of drug particles that have an aerodynamic diameter less than $5 \mu \mathrm{m}$. Such particles can theoretically be deposited in the deep lung after inhalation. The fine-particle fraction (FPF), which is the percentage of the 
FPD usually related to either the nominal dose (total drug mass contained in the device) or the recovered drug (sum of the drug collected in the device and in the different parts of the impingers or impactors after inhalation) (Pilcer et al., 2012).

\subsection{Emitted dose}

The emitted dose expresses the drug mass exiting the device after inhalation. In some cases, FPF can be calculated from emitted dose instead of total or recovered dose of drug from impingers or impactors. The ability of the powder to be fluidised by the airflow through an inhaler is usually indicated by the emission dose, whilst the FPD and FPF measure the capability of the formulation to be fluidised and deagglomerated in time to release the drug from the carrier to be deposited in the appropriate level of the impactors and impingers (Pilcer et al., 2012).

\subsection{Dispersibility}

The dispersibility is calculated as the ratio of FPD to emitted dose (Zeng et al., 2000).

\subsection{Mass median aerodynamic diameter (MMAD)}

Mass median diameter of an aerosol means the particle diameter that has $50 \%$ of the aerosol mass residing above and $50 \%$ of its mass below it. The concept of aerodynamic diameter is central to any aerosol measurements and respiratory drug delivery. The aerodynamic diameter relates the particle to the diameter of a sphere of unit density that has the same settling velocity as the particle of interest regardless of its shape or density. The mass-mean aerodynamic diameter (MMAD) is read from the cumulative distribution curve at the $50 \%$ point (Labiris et al., 2003). The theoretical mass-mean aerodynamic diameter (daero) was determined from the geometric particle size and tap density using the following relationship:

$$
d_{\text {aero }}=d_{\text {geo }}\left[\frac{\left(\rho / \rho_{\text {ref }}\right)^{0.5}}{\gamma}\right]
$$

Where $\mathrm{d}_{\text {geo }}=$ geometric diameter, $\gamma=$ shape factor (for a spherical particle, $\gamma=1$ ), $\mathrm{Q}=$ particle bulk density and @ref=water mass density $\left(1 \mathrm{~g} / \mathrm{cm}^{3}\right)$. Tapped density measurements underestimate particle bulk densities since the volume of particles measured includes the interstitial space between the particles. The true particle density, and the aerodynamic diameter of a given powder, is expected to be slightly larger than reported (El-Gendy et al., 2009).

\subsection{Geometric standard deviation (GSD)}

The degree of dispersity is an important consideration for both quality and efficacy of pharmaceutical aerosols (Chew et al., 2002). The nature of the aerosol distribution must be established accurately if its implications for deposition and efficacy are to be understood 
(Telko et al., 2005). The degree of dispersion in a lognormally distributed aerosol is characterized by the geometric standard deviation (GSD). A larger GSD implies a longer large particle size tail in the distribution(Musante et al., 2002). GSD for a well-functioning stage should ideally be less than 1.2 (the GSD for an ideal size fractionators would be 1.0 and indicates a monodisperse aerosol) (Marple et al., 2003). GSD is a measure of the variability of the particle diameters within the aerosol and is calculated from the ratio of the particle diameter at the $84.1 \%$ point on the cumulative distribution curve to the MMAD. For a log-normal distribution, the GSD is the same for the number, surface area or mass distributions (Labiris et al., 2003). The GSD was determined as

$$
G S D=\sqrt{\frac{\text { sizes } X}{\text { sizes } Y}}
$$

where sizes $X$ and $Y$ are particle sizes for which the line crosses the $84 \%$ and $16 \%$ mark, respectively (Emami et al., 2009).Mostly, particle size distributions are log-normal, for which type of distributions the geometric mean diameter (GMD) and GSD are frequently used as the characteristic parameters. Aerosols from dry powder inhalers are not log-normal however, because they are nearly always a mixture of primary and secondary particles. Agglomerates in the aerosol are the reason for a tail-off at the side of the larger diameters. Therefore, the mass median diameter is a better parameter, although the size fraction for which mass median diameter is calculated should be defined also. For inhalation drugs, the mass median aerodynamic diameter (MMAD) is the most frequently used parameter(Bosquillon et al., 2001).

\section{Carrier qualifications for application in DPIs}

\subsection{Carrier size}

Different and controversy reports have been published about the suitable carrier size for inhalation purposes. Some previous studies have reported improvements in the amount of respirable drug delivered from a DPI by way of reducing the particle size of the carrier (Steckel et al., 1997; Gilani et al., 2004; Louey et al., 2003). For example, increased respirable fraction of salbutamol sulphate (Kassem et al., 1989; Zeng et al., 2000), terbutaline (Kassem et al., 1989), disodium chromoglycate(Braun et al., 1996) and budesonide (Steckel et al., 1997) were concluded with decreased carrier size. It was proposed that smaller agglomerates meet more forceful shear in the turbulent airstreams causing more effective deagglomeration (Islama et al., 2012). However, the use of too small a carrier will result in poor flow properties of the powder, which is one of the primary reasons for incorporating a coarse carrier within the formulation (Zeng et al., 2001).On the other hand, it was reported that larger carrier particles, normally exhibit larger surface discontinuities than fine crystals (De Boer et al., 2003). This may have the advantage of providing shelter to drug particles from the press-on forces during mixing, as the drug particles tend to assemble in these discontinuities during mixing (Iida et al., 2003; De Boer et al., 2005). Therefore, a high carrier particle size does not necessarily have a negative effect on the drug deposition profiles after 
inhalation (Hamishehkar et al., 2010). In a study, formulations of respirable recombinant human granulocyte-colony stimulating factor with larger carriers $(90-125 \mu \mathrm{m})$ showed a higher drug dispersion than the same formulation with $38-75 \mu \mathrm{m}$ carriers, and it is interpreted that this is due to the lower inter-particle forces among the larger sized particles (French et al., 1996). Similar results was shown for enhanced inhalation performance of terbutaline sulphate from a formulation containing coarse lactose $(53-105 \mu \mathrm{m})$ than the same drug containing fine lactose carriers with size less than $53 \mu \mathrm{m}$ (Byron et al., 1990). Recently, an increase in carrier size resulted better aerosolisation behavior of insulin loaded PLGA microparticles mixed with mannitol carrier. The authors conclude that the use of larger particles of mannitol carrier with a lower carrier/microcapsule ratio leads to higher dispersion of the drug due to increase flowability (Hamishehkar et al., 2010).

\subsection{Carrier shape}

Although the influence of carrier particle shape on the drug dispersibility from the DPI formulation is not well recognized but it is known that the attractive forces between drug and carrier particles can be shape dependent (Mullins et al., 1992; Crowder et al., 2001). In fact most commonly used particles for DPI formulations have irregular shapes. In vitro inhalation studies have indicated that elongated (Larhrib et al., 2003; Zeng et al., 2000), needle-like (Ikegami et al., 2002), porous and wrinkled particles (Chew et al., 2005)have improved lung deposition properties of various formulations. Increasing the elongation ratio of the lactose carrier particles also appeared to increase the FPF of salbutamol sulphate (Zeng et al., 2000).Recently, it was reported pollen-shaped hydroxyapatite carrier increased dispersibility of budesonide particles due to reduction in particle interactions (Hassan et al., 2010; 2010). Definitely surface shape effects agglomeration strength but it was also discussed that the aerodynamic diameter of the agglomerates can be changed by shape factor. Because of their larger shape factor, elongated particles have a smaller aerodynamic diameter than spherical particles and thus agglomerations of active drug particles and elongated carriers remain aerosolized for a longer time, and greater distance along the inhalation path, then deagglomeration is enhanced (Islama et al., 2012). The figure 1 shows the presence of loose agglomerates in freeze dried mannitol samples adapted from reference (Hamishehkar et al., 2010), applied mannitol particles in different shapes for formulation of DPI form of insulinloaded biodegradable polymeric microparticles. Spray dried and freeze dried mannitol, both showed smooth surfaces while formulation composed of freeze dried mannitol showed higher FPF and emitted dose than spray dried mannitol. This was interesting when it was found that spray dried mannitol had lower true density than freeze dried mannitol, possible resulting in better emitted dose and consequently improved FPF. This aerosolization behavior of freeze dried mannitol can be attributed to its needle shape particle morphology. Spatial hindering effect of rod shape particles can lead their easier aerosolization, and hence higher emission and higher FPF. The results of FPF and emitted dose for different formulations can partially be explained by elongation ratio and shape factors reported in this article. Freeze dried mannitol had higher elongation ratio and lower shape factor than spray dried mannitol which indicates 
more irregular shape. In vitro inhalation studies have indicated that elongated, fibrous particles improve lung deposition properties (Chan et al., 1989; Fults et al., 1997).

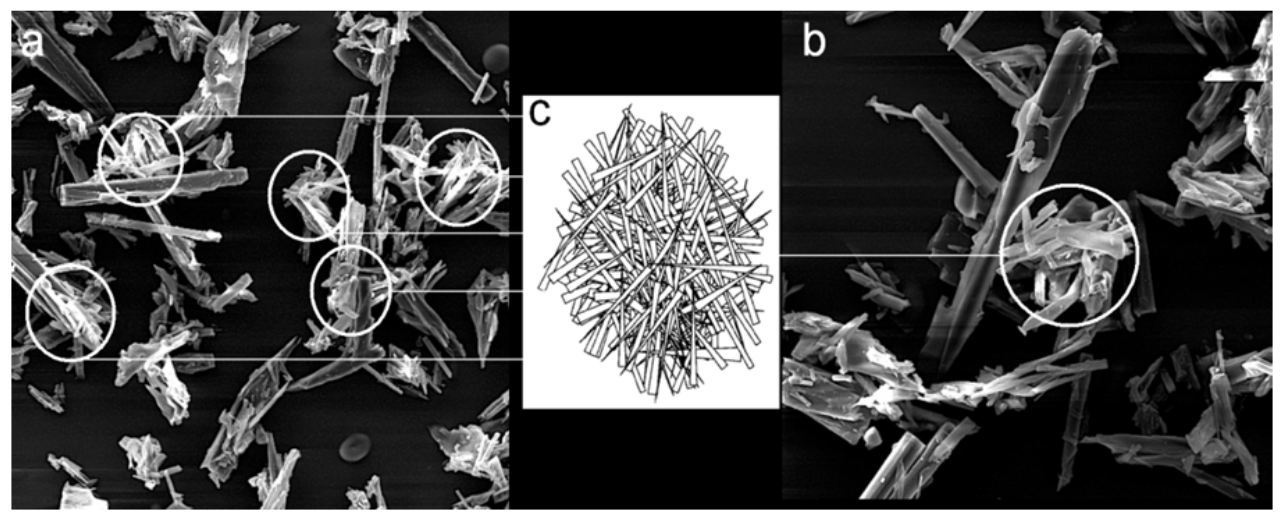

Figure 1. Scanning electron micrographs of freeze-dried mannitol (FDM) $(a, b)$ and schematic image of formed loose agglomerates of needle shape FDM particles (c) adapted from reference (Hamishehkar et al., 2010)

\subsection{Carrier surface}

The in vitro inhalation properties of DPI are reported to be related to the surface properties of the carrier particles (Zeng et al., 2000; Heng et al., 2000; Iida et al., 2001; 2003). Surface morphology has been demonstrated to directly influence the contact area between drug particle and carrier, leading to variations in interparticulate adhesion. Several studies have reported that variations in contact area, as a result of differing surface structure, could potentially compromise the aerosolization performance of the drug particles (Zeng et al., 2000; Flament et al., 2004; Young et al., 2002). Some surface modifications of carrier particles have been reported to improve inhalation performance of DPI (Kawashima et al., 1998; Chan et al., 2003). Previous investigations reported that the carrier surface morphology directly affected the aerosolization efficiency from a DPI (Podczeck, 1998; Larhrib et al., 1999). In general terms, a decrease in roughness is believed to improve aerosolization efficiency of a drug-carrier blend (Ganderton et al., 1992; Kawashima et al., 1998; Zeng et al., 2001). However, it was shown that coarse carrier particles which normally exhibit large surface discontinuities may provide shelter to drug particles from the press-on forces during mixing, as the drug particles tend to assemble in these discontinuities during mixing (Iida et al., 2003). Therefore, high carrier rugosity drug-to-carrier interaction (Kawashima et al., 1998; Podczeck, 1998; Zeng et al., 2000). These interaction forces have to be strong enough to guarantee good mixture stability during handling and proper drug deaggregation does not necessarily have a negative effect on the drug detachment from carrier crystals during inhalation, providing that inertial detachment forces are applied. Chan et al. also reported that a positive linear trend was established between the roughness of the lactose surface and the FPF and dispersibility of the drug (Chan et al., 2003). Therefore, an important balance between the surface morphologies of both the drug and carrier can exist (Young et al., 2002). It was shown by Heng et al. that an optimum lactose surface roughness (Ra) was required 
for an increased fine particle fraction of salbutamol sulphate (Heng et al., 2000). All these studies demonstrated that the different surface roughness of the carrier led to different adhesion forces between the drug and carrier, which was reflected in the in vitro deposition results. The carrier surface plays an important role in, but weak enough to enable the separation forces during inhalation to detach a substantial fraction of the drug dose from the carrier crystals. This requires that the size distributions of the interaction forces (during mixing) and separation forces (during inhalation) are balanced properly (De Boer et al., 2003).The assumed role of carrier surface on the separation of microcapsules aggregation during preparation of DPI formulations and detachment of microcapsules after aerosolization from the surface of carriers is shown schematically in Figure 2 which is adapted from reference (Hamishehkar et al., 2010).This figure shows the dry powder inhalation formulations containing the blend of microcapsules and carriers. It can be seen that there are not enough active sites on the surface of spray dried mannitol and freeze dried mannitol for microcapsules to be deposited on, so carriers cannot disaggregate microcapsules. In the case of sieved sorbitol, microcapsules immersed on the surface of carrier and did not detach easily from its surface after aerosolization. Therefore in spite of better emission of microcapsules from the formulation containing sieved sorbitol, the FPF of the drug decreased. In this article, sieved mannitol showed higher FPF for insulin-loaded PLGA microparticles due to its appropriate surface roughness characteristics.

\subsection{Fine carrier particles}

The addition of fine particles to DPI formulations was shown to improve the inhalation efficiency of drugs (Zeng et al., 1998; Lucas et al., 1998). Islam et al. confirmed that the presence of fine lactose associated with large carriers or added as an excipient, played a key role in the drug dispersion process in this study (Islam et al., 2004). Similar observations were made by Louey et al. using salbutamol sulphate with various lactose carriers (Louey et al., 2003). The addition of ternary components like magnesium stearate and leucine (French et al., 1996; Islam et al., 2004; Staniforth, 1996) has also enhanced drug dispersion by decreasing the cohesive forces between drug particles. The addition of $10 \%$ fine carriers (lactose, glucose, mannitol and sorbitol) in the interactive mixtures of salmeterol xinafoate and coarse carriers demonstrated the same conclusion that fines enhance the detachment of the drug from the large carriers (Adi et al., 2007). On the other hand, the opposite results have been concluded about the role of fines from few studies. It was reported that the concentration of added fine lactose has to be carefully controlled such that a desired dispersibility of the drug can be achieved without substantially affecting powder flow properties (Zeng et al., 1998). The presence of "fines" tend to inhibit flow because fines can fit into the voids between larger particles and encourage packing and consequent powder densification, and fines are inherently poor flowing (Augsburger, 1974) due to various surface forces (Hickey et al., 2007) and high cohesive energy. It was recently reported that the presence of fines caused a decrease in FPF (Steckel et al., 2004; Hamishehkar et al., 2010). Also the use of micronized fine carrier may introduce extra amorphous content to the powder because a large portion of micronized lactose is in the amorphous form, which is thermodynamically unstable and will convert to the more stable crystalline form on 
exposure to moisture (Saleki-Gerhardt et al., 1994). Such a transformation is likely to change the performance characteristics of the bulk powder, such as flowability and drug dispersion (Ward et al., 1994).

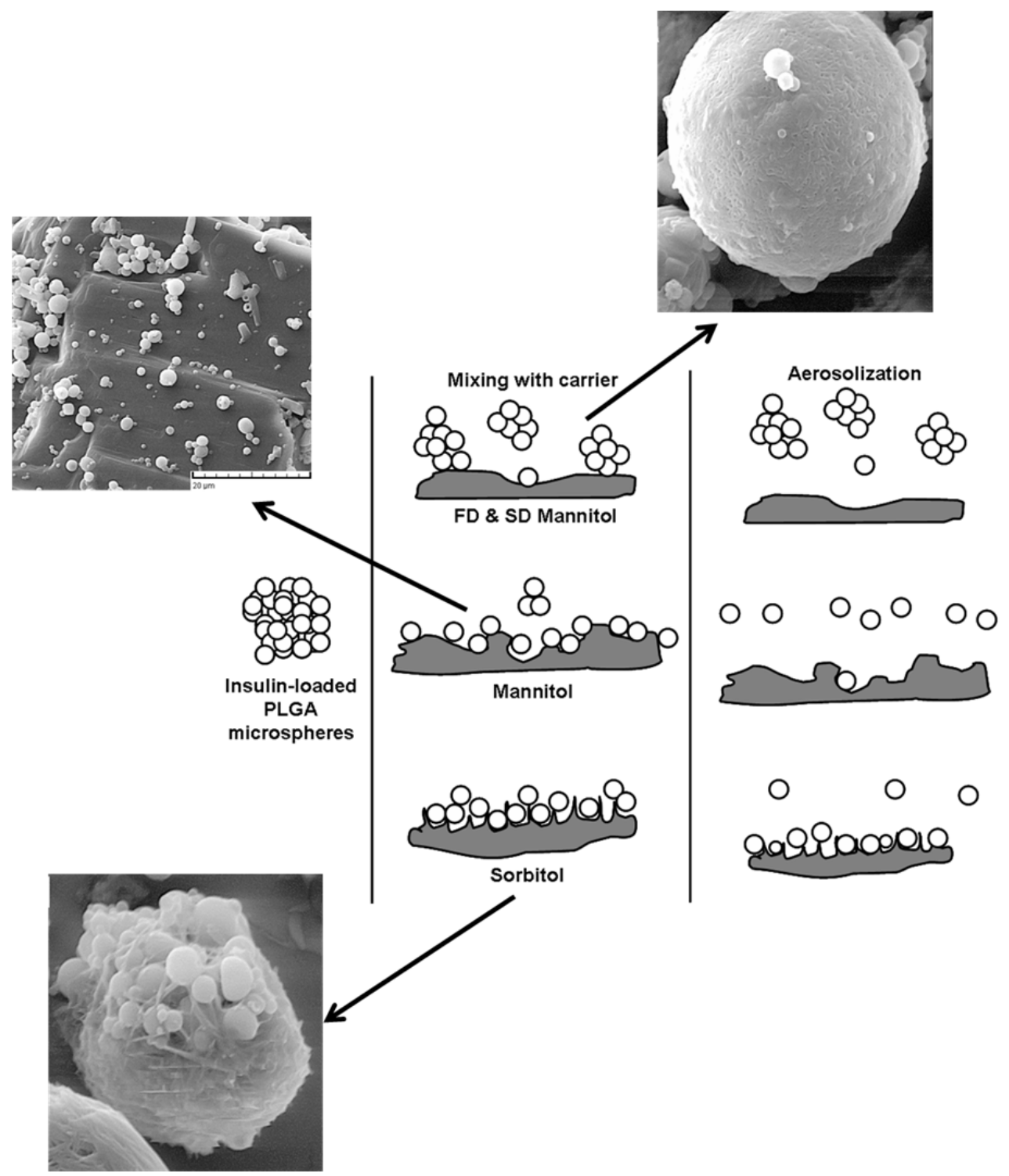

Figure 2. Schematic representation of the role of carrier surface asperities on the drug entrapment and its fluidization capabilities adapted from reference (Hamishehkar et al., 2010). 


\subsection{Carrier crystallinity}

The amorphous part shows a higher surface adhesion energy compared to crystalline surfaces (Young et al., 2004). As a result of increase in adhesion energy, poor deaggregation of drug particles is observed (Podczeck et al., 1997). Therefore it can be hypothesized that, the presence of amorphous material may cause problems, for example, due to the fusion of particles, resulting in poor dispersion (Young et al., 2004; Ward et al., 1995; Podczeck et al., 1997). In addition, the amorphous regions can present difficulties such as decreased chemical stability (Pikal et al., 1978). Partially amorphous or unstable polymorphic forms and changes therein (Harjunen et al., 2002) make the interparticulate contact quite unpredictable and the powder formulation rather unstable (De Boer et al., 2003). It was reported that the maximum fine particle dose of terbutalinesulphate is obtained with the crystallized form of mannitol comparing to different polymorphs of mannitol (Saint-Lorant et al., 2007). Furthermore, previous reports have suggested increased amorphous content in DPI systems resulted in decreased aerosolization performance (Young et al., 2004; Ward et al., 1995).

\section{Lactose as the most frequently used carrier in DPIs}

Lactose, 4-(b-D-galactosido-)-D-glucose, can be obtained in either two basic isomeric forms, $\alpha$ and $\beta$-lactose, or as an amorphous form (Zeng et al., 2000). Historically, lactose monohydrate was an obvious choice for use as a carrier excipient. Lactose accompanying with glucose and mannitol is allowed as carriers in DPIs by the US Food and Drug Administration department (Labiris et al., 2003).Lactose is the most common and frequently used carrier in DPIs formulations and nowadays various inhalation grades of lactose with different physico-chemical properties are available on the market. The advantages of lactose are its well-investigated toxicity profile, physical and chemical stability, compatibility with the drug substance, its broad availability and relatively low price (Steckel et al., 2004; Pilcer et al., 2010). $\alpha$-lactose monohydrate is the most common lactose grade used in the inhalation field.Almost all DPI formulations on the market are based on a-lactose monohydrate as a carrier. Therefore, wealth of literatures refers to the optimization of lactose carrier particles for better inhalation performance. More than 250 articles have been published in the past 40 years regarding the role of lactose in adhesive mixtures used in DPIs. However, in spite of these extensive investigations, the relationship between physico-chemical properties of the lactose in adhesive mixtures and the performance of the DPIs remains largely indistinct (Marriott et al., 2012).

\section{Lactose engineering for application in DPIs}

\subsection{Surface modification}

Iida et al. prepared lactose carrier particles for dry powder inhalations by its surface modification with aqueous ethanol solution and evaluated the inhalation efficiency of salbutamol sulfate from its mixture with modified lactose. The degree of adhesion between drug particles and carrier particles and the separation characteristics of drug particles from carrier particles in air flow were assessed by the ultracentrifuge separation and the air jet 
sieve methods, respectively. It was shown that the average adhesion force between the surfacetreated lactose carrier and drug particles was considerably lower than that of powder mixed with the un-treated lactose carrier, indicating better drug separation from carrier and consequently an improvement of in vitro inhalation properties. The authors claimed that surface-smoothing of lactose by aqueous ethanol solution resulted a well balanced drug-carrier adhesion force so that the drug particles could be emitted together with the carrier particles and efficiently separated in airflow after emission(Iida et al., 2003). Fine lactose particles were immobilized on the lactose surface by spray coating with liquid suspensions consisting of micronized lactose dispersed in isopropyl alcohol and/or water mixtures to modify surface of lactose. The produced lactose was used as a carrier in the formulation of inhalable salbutamol sulfate powder. It was found that the roughness of the lactose surface established by immobilization of fine lactose increased the FPF and dispersibility of the drug. The authors claimed that unlike crevices and valleys, these microscopic undulations did not accommodate the drug particles and instead enhanced the detachment of drug from the lactose surface and improved the drug inhalation efficiency (Chan et al., 2003). Spray dried amorphous, spray dried crystallized and fluidized bed granulated lactose were prepared and used as carrier for inhalation of pranlukast hydrate. Fluidized bed granulated lactose emitted drug particles effectively from the inhalation device, whereas most part of drug captured in the upper stage of twin impinger, resulting in lower inhalation efficiency, due to strong adhesion of drug to the carrier lactose. The spray dried amorphous lactose, smoothed sphere particle, did not so improve the inhalation efficiency as expected, because of fairly strong adhesion between drug and lactose particles. But the spray dried crystallized lactose having lots of microscopical projection on its surface increased the respirable particle percent of the emitted particles. The conclusion was that the surface roughness should be optimized to gain improved inhalation efficiency of particles (Kawashima et al., 1998). In the other study, a Wurster fluidized bed was used for surface-coating of lactose particles with lactose aqueous solution containing hydroxypropyl methyl cellulose. The authors could be able to increase the inhalation performance of salbutamol sulfate 2.5 times more than commercial lactose (Pharmatose ${ }^{\circledR} 200 \mathrm{M}$ ) and reported that surface coating of carrier particles may be an effective technique for improving the inhalation performance of DPI (Iida et al., 2005).Lactose carrier particles were layered with vegetable magnesium stearate by physical mixing and their effect of on the dry powder inhalation properties of salbutamol sulfate was investigated. The in vitro inhalation performance of drug was enhanced compared with the powder mixed with unlayered lactose carrier. It was stated that using this surface layering system would thus be valuable for increasing the inhalation properties of dry powder inhalation (Iida et al., 2004). For example, increasing the surface smoothness of lactose carrier particles was shown to improve the potentially respirable fraction of albuterol sulfate from the Rotahaler $^{\circledR}$ (Littringer et al., 2012).

\subsection{Shape modification}

Lactose crystallization from Carbopol gel in different conditions (named Carbo lactose) produced a more regular shape lactose with smoother surface as compared with the control lactose. The Carbo lactose caused a higher and reproducible salbutamol sulphate emission 
and FPF after aerosolisation via a Rotahaler ${ }^{\circledR}$ tested in multi-stage impinge. It was concluded that engineered crystal growth under controlled conditions can enhance the potential inhalable fraction of drug from dry powder inhalers (Zeng et al., 2001).More recently, the use of more elongated crystals of lactose was also found to produce a higher inhalation efficiency of albuterol sulfate(Zeng et al., 2000).However, the improvement in drug dispersion that can be achieved by increasing the elongation ratio of the carrier particles is limited (Zeng et al., 2001).

\subsection{Composite lactose}

Lactose carrier particles were prepared by fusing sub units of lactose (either2, 6 or $10 \mu \mathrm{m}$ prepared by spray drying) in saturated lactose slurry, sieve fractioned to obtain a 63-90 $\mu \mathrm{m}$ carriers and used for inhalation of salbutamol sulfate. The surface morphology and physicochemical properties of the composite carriers were considerably different from regular $\alpha$ lactose monohydrate.In all cases the composite carriers resulted in improved drug aerosol performance. It was suggested that composite based carriers are a potential route to control drug-carrier adhesion forces and variability thus allowing more precise control of formulation performance (Young et al., 2009 ).

\subsection{Engineered lactose-mannitol mixture}

Mannitol and lactose were co-crystallised to prepare crystals with more desirable characteristics than either lactose or mannitol alone appropriate for application as carriers in the formulations of salbutamol sulfate DPIs. In vitro deposition evaluation showed that crystallized carriers resulted more efficient delivery of salbutamol sulphate compared to formulations containing commercial grade carriers. It was concluded that simultaneous crystallization of lactose-mannitol can be a new approach to enhance inhalation performance of DPI formulations (Kaialy et al., 2012).

\section{Mannitol}

Because of clinical considerations lactose or other sugars cannot be used for drug delivery to diabetic patients. Moreover, for some drugs, e.g., formoterol, or for specific applications, e.g., peptide or protein drugs, lactose monohydrate may not be the carrier of choice due to its reducing sugar function that may interact with functional groups of the drug or the protein (Patton et al., 1992)In addition, lactose monohydrate is produced from bovine or with bovine-driven additives so that the transmissible spongiform encephalopathy (TSE) is still an issue for this compound (European Commission-Health \& Consumer Protection Directorate, 2002)Lactose intolerance is a problem that necessitates the patient to use lactosefree formulations (Glasnapp, 1998).It is therefore logical to look for substitute carriers that still possess the positive aspects but overcome the above mentioned drawbacks of lactose monohydrate (Hamishehkar et al., 2010). Mannitol, a hexahydric alcohol, has been mainly used as a pharmaceutical excipient. Its potential use as a carrier for aerosol delivery has been reported (Tee et al., 2000; Steckel et al., 2004). Mannitol does not have a reducing sugar 
function, is less hygroscopic than lactose (Saint-Lorant et al., 2007)and gives a suitable sweet after-taste which has a benefit to patients confirming them that a dose has been properly administered (Kaialy et al., 2010).Mannitol proved to be the most promising candidate for this application than the more hygroscopic sugar alcohols such as sorbitol, xylitol and maltitol. D-mannitol is currently marketed in some countries as a pulmonary diagnostic dry powder inhalation aerosol (Aridol ${ }^{\mathrm{TM}}$ ) and as a therapeutic dry powder inhalation aerosol for the treatment of cystic fibrosis and chronic bronchitis (Bronchitol ${ }^{\mathrm{TM}}$ ) which are recently approved by US food and drug administration office and a European regulatory committee, respectively(Mansour et al., 2010).Spherical mannitol particles used in Aridol ${ }^{\mathrm{TM}}$ were produced by spray drying (Tang et al., 2009).A DPI formulation for inhalation of ciprofloxacin hydrochloride (an antibacterial fluoroquinolone) was prepared by its co-spray drying with different percentages of mannitol. The combination formulation containing $50 \%$ $(\mathrm{w} / \mathrm{w})$ mannitol showed the best inhaltion performance, good stability and lowest particle cohesion (as measured by colloid probe microscopy). It was proposed that the combination of co-spray-dried mannitol and ciprofloxacin from a DPI is an attractive approach to promote mucous clearance in the respiratory tract while simultaneously treating local chronic infection, such as chronic obstructive pulmonary disease and cystic fibrosis (Adi et al., 2010). Spray drying method was used to prepare several types of mannitol differ in shape and surface roughness. In this study besides the introducing the spray drying method as a proper technique for preparation of mannitol as a carrier for inhlation purposes, it was concluded that the highest fine particle fraction was achieved with carrier particles of spherical shape and a rough surface (Littringer et al., 2012).Despite the above mentioned study, in another study it was shown that the use of elongated mannitol as the carrier particle produced improved DPI performance. It was also indicated that mannitol particles crystallized from either acetone or ethanol ( $\alpha$-mannitol) showed the best aerosolisation performance while poorest aerosolisation performance was obtained from grounded mannitol ( $\beta$-mannitol) (Kaialya et al., 2011).The same research group in another study again reported the better inhalation performance of salbutamol sulfate from elongated mannitol. In this study mannitol was crystallized from different binary mixtures of acetone/water and its carrier role in DPI formulations of salbutamol sulfate was investigated (Kaialy et al., 2010).Mannitol particles, produced by spray drying, have been used commercially (Aridol ${ }^{\mathrm{TM}}$ ) in bronchial provocation test (mannitol particle itself as an active ingredient not as a carrier). In a study, a confined liquid impinging jets (CLIJs) followed by jet milling was applied and introduced as an alternative method for spray drying. Although the inhalation performance of mannitol particles prepared by CLIJ method was not higher than those prepared from spray drying method (FPF 30\% for particles prepared by CLIJ method compared to FPF $47 \%$ of those prepared by spray dying method) but CLIJ method offers several advantages. A main advantage of using the CLIJ method is that it can be scaled up with an acceptable yield as the precipitate can be largely collected and recovered on a filter, compared with spray drying which has a low collection efficiency for fine particles below $2 \mu \mathrm{m}$ (Tang et al., 2009).Lactose, mannitol and glucose were used as the carriers in the formulations of inhalation powders of budesonide and salbutamol sulphate. The highest respirable fraction of drugs were achieved when mannitol was used as the carrier (Harjunen et al., 2003). 


\section{Sorbitol}

Reducing sugars such as lactose may have an impact on the stability of proteins and peptides (Li et al., 1996; Dubost et al., 1996). Actuality, the use of lactose with protein powders may cause a reaction with lysine residues present in the protein, generating lactosylated protein molecules (Cryan, 2005).In this case, polyols such as sorbitol can play a crucial role in the formulation of respirable protein powder. Sorbitol can also serve as stability enhancers during processing. It was reported that the stability of interferon $\beta$ to jet milling, required to produce a respirable powder, was found to be dependent on the presence of sorbitol in the formulation (Platz et al., 1991; Platz et al., 1994).Sorbitol showed a comparable inhalation outcome for salbutamol sulfate with lactose and mannitol but failed to produce efficient dispersion of drug (FPF less than10\%) (Tee et al., 2000).

\section{Erythritol}

Erythritol, a meso-compound of 1,2,3,4-butanetetrol, is a natural occurring sugar alcohol existing in various fruits and fermented foods, as well as in body fluids of humans and animals. Industrially, it is prepared by glucose fermentation (Lopes Jesus et al., 2010). Erythritol has been administered as a suitable excipient in pharmaceutical formulations due to its thermal stability, very low hygroscopicity (Cohen et al., 1993) sweetness taste, low toxicity (Munro et al., 1998) and high compatibility with drugs (Endo et al., 2005; Gonnissen et al., 2007).Due to above desirable characteristics, erythritol was recently entered in the European Pharmacopoiea (Traini et al., 2006). Endo et al. used erythritol as carrier in the DPI formulation of glucagon, a key regulatory element of glycogen metabolism which is known to be effective in the clinical treatment of hypoglycemia and the maintenance of normal circulating glucose levels in patients with total pancreatectomy. This hormone has been restricted to parenteral administration. The in vitro and in vivo studies were indicated the suitability of erythritol for application in DPI formulation. Moreover, it was claimed that this dry powder inhalation of glucagon can be administered to the clinical treatment of hypoglycemia, and the maintenance of normal circulating glucose levels in patients with total pancreatectomy (Endo et al., 2005). In a comparative study, erythritol andlactose monohydrate were used as carriers in the DPI formulation of salbutamol sulfate. Drugcarrier adhesion was measured using atomic force microscope colloid probe technique and showed a higher adhesion force for erythritol than lactose. Consequently lower inhalation performance of salbutamol sulfate was resulted from DPI formulations containing erythritol than lactose. However, it was concluded that even though erythritol may show a reduced DPI functionality, with this drug, it may offer some potential advantages in terms of its reproducible chemical structure and stability (Traini et al., 2006).

\section{Trehalose}

Trehalose dihydrate is a disaccharide sugar and crystalline hydrate like lactose. However, trehalose dihydrate is a non-reducing sugar and lactose monohydrate is a reducing sugar. As a reducing sugar, it participates in solid-state chemical degradation by the Maillard 
reaction with certain types of small molecular weight drugs (such as formoterol and budesonide) and polypeptide/protein-type drugs. Therefore, some attempts have been carried out on the application of trehalose in the formulation of DPIs. In a study, trehalose was used as a carrier for DPI formulation of albuterol sulfate, ipratropium bromide monohydrate, disodium cromoglycate, and fluticasone propionate (Mansour et al., 2010).The highest inhalation performance was reported for the blend of albuterol and ipratropium with trehalose dihydrate in comparison with lactose monohydrate and mannitol (Cline et al., 2002).

\section{Other carriers}

Recently, the feasibility of using pollen-shape hydroxyapatite particles as carrier in DPI formulation of budesonide is investigated. The hydroxyapatite carriers showed better flowability and capability of higher drug attachment than commonly used lactose carrier with similar size range. Consequently, DPI formulations with hydroxyapatite carriers gave higher drug emission and respirable fraction than traditional lactose carriers (Hassan et al., 2010). Many different non-lactose carriers have been investigated, such as cyclodextrins, dextrose, glucose monohydrate, maltitol, maltose, raffinosepentahydrate and xylitol.Anhydrous glucose is already used in the marketed product Bronchodual ${ }^{\circledR}$ (Boehringer) (Pilcer et al., 2010).Sucrose, trehalose and raffinose are non-reducing sugars and as such have the advantage that they will not undergo the Maillard browning reaction with proteins (Ógáin et al., 2011). But in contrast to lactose monohydrate which was found to only take up moisture on its surface, and showing only a small reduction in its FPF after storage at 75\% RH (Young et al., 2007; Zeng etal., 2007), a main difficulty with these sugars, especially with the more hygroscopic substances - sorbitol, maltitol and xylitol - has attributed to their sensitivity to humidity. In fact, the capillary forces, arisen from the dynamic condensation of water molecules onto particle surfaces, seem to be less prominent with mannitol and lactose as carriers, probably because of their less hygroscopic characteristics than the other carbohydrates (Zeng et al., 2007; Young et al., 2007). However, it was proposed that the difficulties arising from their hygroscopicity can be overcome by adding an ultrafine hydrophobic excipient to the powder blend (Steckel et al., 2004).Comparing the different forms of mannitol, lactose and maltitol mixed with terbutaline sulfate resulted in higher FPF with crystallized mannitol for terbutaline sulfate (Saint-Lorant et al., 2007).Hooton et al, used beta cyclodextrin, lactose, raffinose, trehalose and xylitol for the formulation of salbutamol sulfate DPI and applied the cohesive-adhesive balance technique for analyzing quantitative AFM measurements to interpret inhalation behavior of drug. The rank order of the FPF of the salbutamol sulfate based carrier DPI formulations was beta cyclodextrin> lactose $>$ raffinose $>$ trehalose $>$ xylitol which had a linear correlation with cohesive-adhesive ratios of the AFM force measurements (Hooton et al., 2006).

\section{Large porous particles}

A new type of aerosol formulation is the large porous hollow particles. These particles have the mean diameters $>5 \mu \mathrm{m}$ and mass densities $<0.1 \mathrm{~g} / \mathrm{cm}^{3}$ (Edwards et al., 1997). Although 
these particles have large geometric diameters because of their low density, they exhibit aerodynamic diameters comparable to smaller particles having higher densities (Koushik et al., 2004). They may be ideal for pulmonary drug delivery because of their low density and large surface area which causes excellent dispersibility (Labiris et al., 2003). Furthermore, their large geometric size may reduce clearance by macrophage action, thereby improving the bioavailability of inhaled pharmaceuticals (Musante et al., 2002).To show the ability of large porous aerosols to increase systemic bioavailability as well as to provide sustainedrelease capability in the lungs, Edwards et al. encapsulated insulin into a biodegradable polymers and indicated the better inhalation performance and controlled-release capability of these particles in the lung (Edwards et al., 1997).Ungaro et al. confirmed the same observations with delivery of insulin into rat lung by preparation of PLGA large porous particle with the aid of cyclodextrins (Ungaro et al., 2009).These particles can be prepared using polymeric or nonpolymeric excipients, by solvent evaporation and spray-drying techniques (Edwards et al., 1998). Pulmospheres ${ }^{\mathrm{TM}}$ is an example which is made of phosphatidylcholine, the primary component of human lung surfactant (Labiris et al., 2003). In two interesting studies, highly porous large biodegradable polymeric particles were fabricated using ammonium bicarbonate as an effervescent porogen (Ungaro et al., 2010; Yang et al., 2009).

\section{Conclusion}

The number of diseases that are being considered candidates for the aerosol therapy has increased considerably. Until recently, asthma and chronic obstructive pulmonary diseases were only the apparent examples of diseases that could be treated via drug delivery to lungs. But now other pulmonary diseases such as cystic fibrosis, lung cancer and pulmonary infectious diseases and also systemic disorders such as diabetes, cancer, neurobiological disorders are considered to be managed by pulmonary drug delivery. Interest in DPIs has increased in the last decade due to its numerous advantages over other pulmonary drug delivery dosage forms. Currently, the inhalation performance of DPIs are being improved by changing formulation strategy, drug and carrier particle engineering. Regarding formulation development, micronised drug particles are cohesive with poor flow properties. Addition of large carrier particles into powders to enhance their flow characteristics has been an appropriate approach. The main goal in the inhalation field is to obtain reproducible, high pulmonary deposition which can be highly effected by physico-chemical characteristics of carrier. This could be achieved by successful carrier selection and careful process optimization. Technologies for engineering carrier particle shape, density, and size will continue to develop to enhance the effectiveness of pulmonary drug formulations. This approach may enable more drugs to be delivered through this route for local treatment of lung diseases or systemic therapy.

\section{Author details}

Hamed Hamishehkar

Pharmaceutical Technology Laboratory, Drug Applied Research Center, Tabriz University of Medical Sciences, Tabriz, Iran 
Yahya Rahimpour

Student Research Committee and Faculty of Pharmacy,

Tabriz University of Medical Sciences, Tabriz, Iran

Yousef Javadzadeh *

Biotechnology Research Center andFaculty of Pharmacy,

Tabriz University of Medical Sciences, Tabriz, Iran

\section{References}

Adi, H.; Larson, I. \& Stewart, P.J., (2007). Adhesion and redistribution of salmeterol xinafoate particles in sugar-based mixtures for inhalation. Int J Pharm, Vol. 337, No. 1-2, pp. 229-238, ISSN: 0378-5173.

Adi, H.; Young, P.M.; Chan, H.-K.; Agus, H. \& Traini, D., (2010). Co-spray-dried mannitolciprofloxacin dry powder inhaler formulation for cystic fibrosis and chronic obstructive pulmonary disease. Eur J Pharm Sci, Vol. 40, pp. 239-247, ISSN: 0928-0987.

Ali, R.; Jain, G.K.; Iqbal, Z.; Talegaonkar, S.; Pandit, P.; Sule, S.; Malhotra, G.; Khar, R.K.; Bhatnagar, A. \& Ahmad, F.J., (2009). Development and clinical trial of nano-atropine sulfate dry powder inhaler as a novel organophosphorous poisoning antidote. Nanomed-Nanotechnol, Vol. 5, No. 1, pp. 55-63, ISSN: 1549-9634.

Anon, (2008). Method of and apparatus for effecting delivery of fine powders. IP Com J, Vol. 8 , No. 1B, pp. 13 ,

Atkins, P.J., (2005). Dry powder inhalers: an overview. Resp Care, Vol. 50, No. 10, pp. 13041312, ISSN: 0020-1324.

Augsburger, L.L., (1974). Powdered dosage forms. Sprowls' American Pharmacy: An Introduction to Pharmaceutical Techniques and Dosage Forms 7th ed Philadelphia: JB Lippincott Company, pp. 301-343,

Bosquillon, C.; Lombry, C.; Preat, V. \& Vanbever, R., (2001). Influence of formulation excipients and physical characteristics of inhalation dry powders on their aerosolization performance. J Control Release, Vol. 70, No. 3, pp. 329-339, ISSN: 0168-3659.

Braun, M.A.; Oschmann, R. \& Schmidt, P.C., (1996). Influence of excipients and storage humidity on the deposition of disodium cromoglycate (DSCG) in the twin impinger. Int J Pharm, Vol. 135, No. 1, pp. 53-62, ISSN: 0378-5173.

Byron, P.R. \& Jashnani, R., (1990). Efficiency of aerosolization from dry powder blends of terbutaline sulphate and lactose NF with different particle size distributions. Pharm Res, Vol. 7, pp. S81, ISSN: 0724-8741.

Carpenter, J.F.; Pikal, M.J.; Chang, B.S. \& Randolph, T.W., (1997). Rational design of stable lyophilized protein formulations: some practical advice. Pharm Res, Vol. 14, pp. 969-975, ISSN: 0724-8741.

Chan, H.K. \& Gonda, I., (1989). Aerodynamic properties of elongated particles of cromoglycic acid. J Aerosol Sci, Vol. 20, No. 2, pp. 157-168, ISSN: 0021-8502.

* Corresponding Author 
Chan, L.W.; Lim, L.T. \& Heng, P.W.S., (2003). Immobilization of fine particles on lactose carrier by precision coating and its effect on the performance of dry powder formulations. J Pharm Sci, Vol. 92, No. 5, pp. 975-984, ISSN: 1520-6017.

Cheatham, W.W.; Leone-Bay, A.; Grant, M.; Fog, P.B. \& Diamond, D.C., (2006). Pulmonary delivery of inhibitors of phosphodiesterase type 5. Application: WO. USA: Mannkind Corporation; p. 23 .

Chew, N.Y. \& Chan, H.K., (2002). Effect of powder polydispersity on aerosol generation. J Pharm Pharm Sci Vol. 5, pp. 162-168, ISSN: 1482-1826.

Chew, N.Y.K.; Tang, P.; Chan, H.K. \& Raper, J.A., (2005). How much particle surface corrugation is sufficient to improve aerosol performance of powders? Pharm Res, Vol. 22, No. 1, pp. 148-152, ISSN: 0724-8741.

Cline, D. \& Dalby, R., (2002). Predicting the quality of powders for inhalation from surface energy and area. Pharm Res, Vol. 19, No. 9, pp. 1274-1277, ISSN: 0724-8741.

Cohen, S.; Marcus, Y.; Migron, Y.; Dikstein, S. \& Shafran, A., (1993). Water sorption, binding and solubility of polyols. J Chem Soc, Faraday Trans, Vol. 89, pp. 3271-3275,

Crowder, T.M.; Louey, M.D.; Sethuraman, V.V.; Smyth, H.D.C. \& Hickey, A.J., (2001). An odyssey in inhaler formulation and design. Pharm Technol, Vol. 25, No. 7, pp. 99-113, ISSN: 0147-8087.

Crowder, T.M.; Rosati, J.A.; Schroeter, J.D.; Hickey, A.J. \& Martonen, T.B., (2002). Fundamental effects of particle morphology on lung delivery: Predictions of Stokes' law and the particular relevance to dry powder inhaler formulation and development. Pharm Res, Vol. 19, No. 3, pp. 239-245, ISSN: 0724-8741.

Cryan, S.A., (2005). Carrier-based strategies for targeting protein and peptide drugs to the lungs. The AAPS journal, Vol. 7, No. 1, pp. 20-41,

De Boer, A.H.; Dickhoff, B.H.J.; Hagedoorn, P.; Gjaltema, D.; Goede, J.; Lambregts, D. \& Frijlink, H.W., (2005). A critical evaluation of the relevant parameters for drug redispersion from adhesive mixtures during inhalation. Int J Pharm, Vol. 294, No. 1, pp. 173-184, ISSN: 0378-5173.

De Boer, A.H.; Hagedoorn, P.; Gjaltema, D.; Goede, J. \& Frijlink, H.W., (2003). Air classifier technology $(\mathrm{ACT})$ in dry powder inhalation. Part 1. Application of a Force Distribution Concept (FDC) to explain the performance of a basic classifier on adhesive mixtures. Int J Pharm, Vol. 260, pp. 187-200, ISSN: 0378-5173.

De Boer, A.H.; Hagedoorn, P.; Gjaltema, D.; Goede, J.; Kussendrager, K.D. \& Frijlink, H.W., (2003). Air classifier technology (ACT) in dry powder inhalation Part 2. The effect of lactose carrier surface properties on the drug-to-carrier interaction in adhesive mixtures for inhalation. Int J Pharm, Vol. 260, No. 2, pp. 201-216, ISSN: 0378-5173.

Dubost, D.C.; M.J., K.; Zimmerman, J.A.; Bogusky, M.J.; Coddington, A.B. \& Pitzenberger, S.M., (1996). Characterization of a solid state reaction product from a lyophilized formulation of a cyclic heptapeptide: a novel example of an excipient-induced oxidation. Pharm Res, Vol. 13, pp. 1811-1814, ISSN: 0724-8741. 
Edwards, D.A.; Chen, D.; Wang, J. \& Ben-Jebria, A., (1998). Controlled-release inhalation aerosols. In Respiratory drug delivery, 6th edn, eds Dalby RN, Byron PR, Farr SJ. Buffalo Grove, IL: Interpharm Press Inc., 187-192.

Edwards, D.A.; Hanes, J.; Caponetti, G.; Hrkach, J.; Ben-Jebria, A. \& Eskew, M.L., (1997). Large porous particles for pulmonary drug delivery. Science, Vol. 276, pp. 1868-1871, ISSN: 0036-8075.

Edwards, D.A.; Sung, J.; Pulliam, B.; Wehrenberg-Klee, E.; Schwartz, E.; Dreyfuss, P. \& al., e., (2005). Pulmonary delivery of malarial vaccine in the form of particulates.Application:WO: USA: President and Fellows of Harvard College; p. 25

El-Gendy, N. \& Berkland, C., (2009). Combination chemotherapeutic dry powder aerosols via controlled nanoparticle agglomeration. Pharm Res, Vol. 26, No. 7, pp. 1752-1763, ISSN: 0724-8741.

Emami, J.; Hamishehkar, H.; Najafabadi, A.R.; Gilani, K.; Minaiyan, M.; Mahdavi, H.; Mirzadeh, H.; Fakhari, A. \& Nokhodchi, A., (2009). Particle size design of PLGA microspheres for potential pulmonary drug delivery using response surface methodology. J Microencapsul, Vol. 26, No. 1, pp. 1-8, ISSN: 1464-5246.

Endo, K.; Amikawa, S.; Matsumoto, A.; Sahashi, N. \& Onoue, S., (2005). Erythritol-based dry powder of glucagon for pulmonary administration. Int J Pharm, Vol. 290, pp. 63-71, ISSN: 0378-5173.

European Commission-Health \& Consumer Protection Directorate, (2002). Provisional statement on the safety of calf-derived rennet for the manufacture of pharmaceutical grade lactose.

Farr, S.J. \& Otulana, B.A., (2006). Pulmonary delivery of opioids as pain therapeutics. Adv Drug Deliv Rev, Vol. 58, No. 9, pp. 1076-1088, ISSN: 0169-409X.

Flament, M.P.; Leterme, P. \& Gayot, A., (2004). The influence of carrier roughness on adhesion, content uniformity and the in vitro deposition of terbutaline sulphate from dry powder inhalers. Int J Pharm, Vol. 275, No. 1, pp. 201-209, ISSN: 0378-5173.

Fleischer, W.; Reimer, K. \& Leyendecker, P. Opioids for the treatment of the chronic obstructive pulmonary disease. Euro-Celtique S.A2005.

French, D.L.; Edwards, D.A. \& Niven, R.W., (1996). The influence of formulation on emission, deaggregation and deposition of dry powders for inhalation. J Aerosol Sci, Vol. 27, No. 5, pp. 769-783, ISSN: 0021-8502.

Fults, K.A.; Miller, I.F. \& Hickey, A.J., (1997). Effect of particle morphology on emitted dose of fatty acid-treated disodium cromoglycate powder aerosols. Pharm Dev Technol, Vol. 2, No. 1, pp. 67-79, ISSN: 1083-7450.

Furness, G., (2005). Is systemic pulmonary delivery really in a make-or-break position? . Pharm Dev Technol, Vol. 5 No. pp. 24-27, ISSN: 1083-7450.

Ganderton, D. \& Kassem, N.M., (1992). Dry powder inhalers. Adv Pharm Sci, Vol. 6, No. pp. 165-191,

Geller, D.E.; M.W., K.; Smith, J.; Noonberg, S.B. \& Conrad, C., (2007). Novel tobramycin inhalation powder in cystic fibrosis subjects: pharmacokinetics and safety. Pediatr Pulm Vol. 42, pp. 307-313, ISSN: 8755-6863. 
Gilani, K.; Najafabadi, A.R.; Darabi, M.; Barghi, M. \& Rafiee-Tehrani, M., (2004). Influence of formulation variables and inhalation device on the deposition profiles of cromolyn sodium dry powder aerosols. DARU J Pharm Sci, Vol. 12, No. 3, ISSN: 1560-8115.

Gonnissen, Y.; Remon, J.P. \& Vervaet, C., (2007). Development of directly compressible powders via co-spray drying Eur J Pharm Biopharm, Vol. 67, pp. 220-226, ISSN: 09396411.

Hamishehkar, H.; Emami, J.; Najafabadi, A.R.; Gilani, K.; Minaiyan, M.; Hassanzadeh, K.; Mahdavi, H.; Koohsoltani, M. \& Nokhodchi, A., (2010). Pharmacokinetics and pharmacodynamics of controlled release insulin loaded PLGA microcapsules using dry powder inhaler in diabetic rats. Biopharm Drug Dispos, Vol. 31, No. 2-3, pp. 189-201, ISSN: 1099-081X

Hamishehkar, H.; Emami, J.; Najafabadi, A.R.; Gilani, K.; Minaiyan, M.; Mahdavi, H. \& Nokhodchi, A. Do fines always improve dry powder inhalation performance? Lactose as a carrier for inhalation products congress; 2010; Parma-Italy2010.

Hamishehkar, H.; Emami, J.; Najafabadi, A.R.; Gilani, K.; Minaiyan, M.; Mahdavi, H. \& Nokhodchi, A., (2010). Effect of carrier morphology and surface characteristics on the development of respirable PLGA microcapsules for sustained-release pulmonary delivery of insulin. Int J Pharm, Vol. 389, No. 1-2, pp. 74-85, ISSN: 1873-3476

Hamishehkar, H.; Emami, J.; Najafabadi, A.R.; Gilani, K.; Minaiyan, M.; Mahdavi, H. \& Nokhodchi, A., (2010). Influence of carrier particle size, carrier ratio and addition of fine ternary particles on the dry powder inhalation performance of insulin-loaded PLGA microcapsules. Powder Technol, Vol. 201 pp. 289-295, ISSN: 0032-5910.

Harjunen, P.; Lankinen, T.; Salonen, H.; Lehto, V.P. \& Järvinen, K., (2003). Effects of carriers and storage of formulation on the lung deposition of a hydrophobic and hydrophilic drug from a DPI. Int J Pharm, Vol. 263, No. 1, pp. 151-163, ISSN: 0378-5173.

Harjunen, P.; Lehto, V.P.; Martimo, K.; Suihko, E.; Lankinen, T.; Paronen, P. \& Järvinen, K., (2002). Lactose modifications enhance its drug performance in the novel multiple dose Taifun® DPI. Eur J Pharm Sci, Vol. 16, No. 4-5, pp. 313-321, ISSN: 0928-0987.

Hassan, M.S. \& Lau, R., (2010). Feasibility study of pollen-shape drug carriers in dry powder inhalation. J Pharm Sci, Vol. 99, pp. 1309-1321, ISSN: 1520-6017.

Hassan, M.S. \& Lau, R., (2010). Inhalation performance of pollen-shape carrier in dry powder formulation with different drug mixing ratios: comparison with lactose carrier. Int J Pharm, Vol. 386, pp. 6-14, ISSN: 0378-5173.

Heng, P.W.S.; Chan, L.W. \& Lim, L.T., (2000). Quantification of the surface morphologies of lactose carriers and their effect on the in vitro deposition of salbutamol sulphate. Chem Pharm Bull, Vol. 48, pp. 393-398, ISSN: 0009-2363.

Heyder, J.; Gebhart, J.; Rudolf, G.; Schiller, C.F. \& Stahlhofen, W., (1986). “Deposition of particles in the human respiratory tract in the size range $0.005-5 \mu \mathrm{m}$ ". J Aerosol Sci, Vol. 17, No. 5, pp. 811-825, ISSN: 0021-8502.

Hickey, A.J.; Lu, D.; Ashley, E.D. \& Stout, J., (2006). Inhaled azithromycin therapy J Aerosol Med, Vol. 19, pp. 54-60, 
Hickey, A.J.; Mansour, H.M.; Telko, M.J.; Xu, Z.; Smyth, H.D.C.; Mulder, T.; Mclean, R.; Langridge, J. \& Papadopoulos, D., (2007). Physical characterization of component particles included in dry powder inhalers. II. Dynamic characteristics. J Pharm Sci, Vol. 96, pp. 1302-1319, ISSN: 1520-6017.

Hooton, J.C.; Jones, M.D. \& Price, R., (2006). Predicting the behavior of novel sugar carriers for dry powder inhaler formulations via the use of a cohesive-adhesive force balance approach. J Pharm Sci, Vol. 95, No. 6, pp. 1288-1297, ISSN: 1520-6017.

Iida, K.; Hayakawa, Y.; Okamoto, H.; Danjo, K. \& Leuenberger, H., (2001). Evaluation of flow properties of dry powder inhalation of salbutamol sulfate with lactose carrier. Chem Pharm Bull, Vol. 49, No. 10, pp. 1326-1330, ISSN: 0009-2363.

Iida, K.; Hayakawa, Y.; Okamoto, H.; Danjo, K. \& Leuenberger, H., (2003). Preparation of dry powder inhalation by surface treatment of lactose carrier particles. Chem Pharm Bull, Vol. 51, No. 1, pp. 1-5, ISSN: 0009-2363.

Iida, K.; Hayakawa, Y.; Okamoto, H.; Danjo, K. \& Luenberger, H., (2003). Effect of surface covering of lactose carrier particles on dry powder inhalation properties of salbutamol sulfate. Chem Pharm Bull, Vol. 51, No. 12, pp. 1455-1457., ISSN: 0009-2363.

Iida, K.; Hayakawa, Y.; Okamoto, H.; Danjo, K. \& Luenbergerb, H., (2004). Effect of surface layering time of lactose carrier particles on dry powder inhalation properties of salbutamol sulfate. Chem Pharm Bull, Vol. 52 No. 3, pp. 350-353, ISSN: 0009-2363.

Iida, K.; Todo, H.; Okamoto, H.; Danjo, K. \& Leuenberger, H., (2005). Preparation of dry powder inhalation with lactose carrier particles surface-coated using a Wurster fluidized bed. Chem Pharm Bull, Vol. 53, No. 4, pp. 431-434, ISSN: 0009-2363.

Ikegami, K.; Kawashima, Y.; Takeuchi, H.; Yamamoto, H.; Isshiki, N.; Momose, D. \& Ouchi, K., (2002). Improved inhalation behavior of steroid KSR-592 in vitro with Jethaler® by polymorphic transformation to needle-like crystals ( $\beta$-form). Pharm Res, Vol. 19, No. 10, pp. 1439-1445, ISSN: 0724-8741.

Islam, N.; Stewart, P.; Larson, I. \& Hartley, P., ( 2004). Lactose surface modification by decantation: are drug-fine lactose ratios the key to better dispersion of salmeterol xinafoate from lactose-interactive mixtures? Pharm Res, Vol. 21, No. 3, pp. 492-499, ISSN: 0724-8741.

Islama, N. \& Clearyb, M.J., (2012). Developing an efficient and reliable dry powder inhaler for pulmonary drug delivery - A review for multidisciplinary researchers. Med Eng Phs, Vol. 34, pp. 409-427, ISSN: 1350-4533.

Kaialy, W.; Larhrib, H.; Martin, G.P. \& Nokhodchi, A., (2012). The effect of engineered mannitol-lactose mixture on dry powder inhaler performance. Pharm Res, pp. 1-18, ISSN: 0724-8741.

Kaialy, W.; Martin, G.P.; Ticehurst, M.D.; Momin, M.N. \& Nokhodchi, A., (2010). The enhanced aerosol performance of salbutamol from dry powders containing engineered mannitol as excipient. Int J Pharm, Vol. 392, No. 1, pp. 178-188, ISSN: 0378-5173.

Kaialy, W.; Alhalaweh, A.; Velaga, S.P. \& Nokhodchi, A., (2011). Effect of carrier particle shape on dry powder inhaler performance. Int J Pharm, Vol. 421, pp. 12-23, ISSN: 03785173. 
Kassem, N.M.; Ho, K.K.1. \& Ganderton, D., (1989). The effect of air flow and carrier size on the characteristics of an inspirable cloud. J Pharm Pharmacol, ISSN: 0022-3573.

Kawashima, Y.; Serigano, T.; Hino, T.; Yamamoto, H. \& Takeuchi, H., (1998). Effect of surface morphology of carrier lactose on dry powder inhalation property of pranlukast hydrate. Int J Pharm, Vol. 172, No. 1, pp. 179-188, ISSN: 0378-5173.

Kleinstreuer, C.; Zhang, Z. \& Donohue, J.F., (2008). Targeted drug-aerosol delivery in the human respiratory system. Annu Rev Biomed Eng, Vol. 10, pp. 195-220, ISSN: 1523-9829.

Koushik, K. \& Kompella, U.B., ( 2004). Preparation of large porous deslorelin-PLGA microparticles with reduced residual solvent and cellular uptake using a supercritical carbon dioxide process. Pharm Res, Vol. 21, No. 3, pp. 524-535, ISSN: 0724-8741.

Labiris, N.R. \& Dolovich, M.B., (2003). Pulmonary drug delivery. Part I: Physiological factors affecting therapeutic effectiveness of aerosolized medications. Br J Clin Pharmacol, Vol. 56, pp. 588-599, ISSN: 1365-2125.

Labiris, N.R. \& Dolovich, M.B., (2003). Pulmonary drug delivery. Part II: the role of inhalant delivery devices and drug formulations in therapeutic effectiveness of aerosolized medications. Br J Clin Pharmacol, Vol. 56, No. 6, pp. 600-612, ISSN: 1365-2125.

Larhrib, H.; Martin, G.P.; Marriott, C. \& Prime, D., (2003). The influence of carrier and drug morphology on drug delivery from dry powder formulations. Int J Pharm, Vol. 257, No. 1, pp. 283-296, ISSN: 0378-5173.

Larhrib, H.; Zeng, X.M.; Martin, G.P.; Marriott, C. \& Pritchard, J., (1999). The use of different grades of lactose as a carrier for aerosolised salbutamol sulphate. Int J Pharm, Vol. 191, No. 1, pp. 1-14, ISSN: 0378-5173.

Laube, B.L., (2005). The expanding role of aerosols in systemic drug delivery, gene therapy, and vaccination. Resp Care, Vol. 50, No. 9, pp. 1161-1176, ISSN: 0020-1324.

Li, S.; Patapoff, T.W.; Overcashier, D.; Hsu, C.; Nguyen, T.H. \& Borchardt, R.T., (1996). Effects of reducing sugars on the chemical stability of human relaxin in the lyophilized state. J Pharm Sci, Vol. 85, pp. 873-877, ISSN: 1520-6017.

LiCalsi, C.; Maniaci, M.J.; Christensen, T.; Phillips, E.; Ward, G.H. \& Witham, C., (2001). A powder formulation of measles vaccine for aerosol delivery. Vaccine, Vol. 19, No. 17, pp. 2629-2636, ISSN: 0264-410X.

Littringer, E.; Mescher, A.; Schroettner, H.; Achelis, L.; Walzel, P. \& Urbanetz, N., (2012). Spray dried mannitol carrier particles with tailored surface properties-The influence of carrier surface roughness and shape. Eur J Pharm Biopharm, ISSN: 0939-6411.

Littringer, E.M.; Mescher, A.; Schroettner, H.; Achelis, L.; Walzel, P. \& Urbanetz, N.A., (2012). Spray dried mannitol carrier particles with tailored surface properties -The influence of carrier surface roughness and shape. Eur J Pharm Biopharm http://dxdoiorg/101016/jejpb201205001, ISSN: 0939-6411.

Lopes Jesus, A.J.; Nunes, S.C.C.; Ramos Silva, M.; Matos Beja, A. \& Redinha, J., (2010). Erythritol: Crystal growth from the melt. Int J Pharm, Vol. 388, No. 1-2, pp. 129-135, ISSN: 0378-5173. 
Louey, M.D.; Razia, S. \& Stewart, P.J., (2003). Influence of physico-chemical carrier properties on the in vitro aerosol deposition from interactive mixtures. Int J Pharm, Vol. 252, No. 1, pp. 87-98, ISSN: 0378-5173.

Lucas, P.; Anderson, K. \& Staniforth, J.N., (1998). Protein deposition from dry powder inhalers: fine particle multiplets as performance modifiers. Pharm Res, Vol. 15, No. 4, pp. 562-569, ISSN: 0724-8741.

Mansour, H.M.; Xu, Z. \& Hickey, A.J., (2010). Dry powder aerosols generated by standardized entrainment tubes from alternative sugar blends: 3.Trehalose dihydrate and D-mannitol carriers. J Pharm Sci, Vol. 99, No. 8, pp. 3430-3441, ISSN: 1520-6017.

Marianecci, C.; Di Marzio, L.; Rinaldi, F.; Carafa, M. \& Alhaique, F., (2011). Pulmonary delivery: innovative approaches and perspectives. Journal of Biomaterials and Nanobiotechnology, Vol. 2, No. 5, pp. 567-575, ISSN: 2158-7027.

Marple, V.A.; Olson, B.A.; Santhanakrishnan, K.; Mitchell, J.P.; Murray, S.C. \& HudsonCurtis, B.L., (2003). Next generation pharmaceutical impactor. Part II: Calibration. . J Aerosol Med, Vol. 16, pp. 301-324,

Marriott, C. \& Frijlink, H.W., (2012). Lactose as a carrier for inhalation products: breathing new life into an old carrier. Adv Drug Deliv Rev, Vol. 64, No. 3, pp. 217, ISSN: 0169-409X.

Mullins, M.E.; Michaels, L.P.; Menon, V.; Locke, B. \& Ranade, M.B., (1992). Effect of geometry on particle adhesion. Aerosol Sci Tech, Vol. 17, No. 2, pp. 105-118, ISSN: 02786826.

Munro, I.C.; Bernt, W.O.; Borzelleca, J.F.; Flamm, G.; Lynch, B.S.; Kennepohl, E.; Bär, E.A. \& Modderman, J., (1998). Erythritol: an interpretive summary of biochemical,metabolic, toxicological and clinical data. Food Chem Toxicol Vol. 36, pp. 1139-1174, ISSN: 02786915.

Musante, C.J.; Schroeter, J.D.; Rosati, J.A.; Crowder, T.M.; Hickey, A.J. \& Martonen, T.B., (2002). Factors affecting the deposition of inhaled porous drug particles. J Pharm Sci, Vol. 91, No. 7, pp. 1590-1600, ISSN: 1520-6017.

Ógáin, O.N.; Li, J.; Tajber, L.; Corrigan, O.I. \& Healy, A.M., (2011). Particle engineering of materials for oral inhalation by dry powder inhalers. I-Particles of sugar excipients (trehalose and raffinose) for protein delivery. Int J Pharm, Vol. 405, No. 1, pp. 23-35, ISSN: 0378-5173.

Patton, J.S. \& Bossard, M.J., (2004). Drug delivery strategies for proteins and peptides from discovery and development to life cycle management. Pharm Dev Technol, Vol. 4, No. 8, pp. 73-77, ISSN: 1083-7450.

Patton, J.S. \& Platz, R.M., (1992). Pulmonary delivery of peptides and proteins for systemic action. Adv Drug Deliv Rev, Vol. 8, pp. 179-228, ISSN: 0169-409X.

Pikal, M.J.; Lukes, A.L.; Lang, J.E. \& Gaines, K., (1978). Quantitative crystallinity determinations for beta-lactamantibiotics by solution calorimetry: correlations with stability. J Pharm Sci, Vol. 67, pp. 767-772, ISSN: 1520-6017.

Pilcer, G. \& Amighi, K., (2010). Formulation strategy and use of excipients in pulmonary drug delivery. Int J Pharm, Vol. 392, pp. 1-19, ISSN: 0378-5173. 
Pilcer, G.; Wauthoz, N. \& Amighi, K., (2012). Lactose characteristics and the generation of the aerosol. Adv Drug Deliv Rev, Vol. 64 pp. 233-256, ISSN: 0169-409X.

Platz, R.; Ip, A. \& Whitham, C.L., (1994). Process for preparing micronized polypeptide drugs.US Patent 5,354,562., Vol., No.

Platz, R.; Utsumi, J.; Satoh, Y. \& Naruse, N. Pharmaceutical aerosol formulation of solid polypeptide microparticles and method for the preparation thereof. World Patent 9,116,038. 1991.

Plumley, C.; Gorman, E.M.; El-Gendy, N.; Bybee, C.R.; Munson, E.J. \& Berkland, C., (2009). Nifedipine nanoparticle agglomeration as a dry powder aerosol formulation strategy. Int J Pharm, Vol. 369, No. 1-2, pp. 136-143, ISSN: 0378-5173.

Podczeck, F., (1998). The relationship between physical properties of lactose monohydrate and the aerodynamic behaviour of adhered drug particles. Int J Pharm, Vol. 160, No. 1, pp. 119-130, ISSN: 0378-5173.

Podczeck, F.; Newton, J.M. \& James, M.B., (1997). Variations in the adhesion force between a drug and carrier particles as a result of changes in the relative humidity of the air. Int $J$ Pharm, Vol. 149, pp. 151-160, ISSN: 0378-5173.

Prime, D.; Atkins, P.J.; Slater, A. \& Sumby, B., (1997). Review of dry powder inhalers. Adv Drug Deliv Rev, Vol. 26, No. 1, pp. 51-58, ISSN: 0169-409X.

Rawat, A.; Majumder, Q.H. \& Ahsan, F., (2008). Inhalable large porous microspheres of low molecular weight heparin: in vitro and in vivo evaluation. J Control Release, Vol. 128, No. 3, pp. 224-232, ISSN: 0168-3659.

Rytting, E.; Nguyen, J.; Wang, X. \& Kissel, T., (2008). Biodegradable polymeric nanocarriers for pulmonary drug delivery. Expert Opin Drug Deliv, Vol. 5, No. 6, pp. 629-639 ISSN: 1742-5247.

Saint-Lorant, G.; Leterme, P.; Gayot, A. \& Flament, M.P., (2007). Influence of carrier on the performance of dry powder inhalers. Int J Pharm, Vol. 334, No. 1, pp. 85-91, ISSN: 03785173.

Sakagami, M., (2006). In vivo, in vitro and ex vivo models to assess pulmonary absorption and disposition of inhaled therapeutics for systemic delivery. Adv Drug Deliv Rev, Vol. 58, No. 9, pp. 1030-1060, ISSN: 0169-409X.

Saleki-Gerhardt, A.; Ahlneck, C. \& Zografi, G., (1994). Assessment of disorder in crystalline solids. Int J Pharm, Vol. 101, pp. 237-247, ISSN: 0378-5173.

Schiavone, H.; Palakodaty, S.; Clark, A.; York, P. \& Tzannis, S.T., (2004). Evaluation of SCFengineered particle-based lactose blends in passive dry powder inhalers. Int J Pharm, Vol. 281, No. 1, pp. 55-66, ISSN: 0378-5173.

Staniforth, J.N., (1996). Improvement in dry powder inhaler performance: surface passivation effects. Drug Delivery to the Lungs VII.

Steckel, H. \& Bolzen, N., (2004). Alternative sugars as potential carriers for dry powder inhalations. Int J Pharm, Vol. 270, No. 1, pp. 297-306, ISSN: 0378-5173.

Steckel, H.; Markefka, P.; TeWierik, H. \& Kammelar, R., (2004). Functionality testing of inhalation grade lactose. Eur J Pharm Biopharm, Vol. 57, No. 3, pp. 495-505, ISSN: 09396411. 
Steckel, H. \& Muller, B.W., (1997). In vitro evaluation of dry powder inhalers II: influence of carrier particle size and concentration on in vitro deposition. Int J Pharm, Vol. 154, No. 1, pp. 31-37, ISSN: 0378-5173.

Stoessl, A.J., (2008). Potential therapeutic targets for Parkinson's disease. Expert Opin Ther Tar Vol. 12, pp. 425-436, ISSN: 1472-8222.

Tang, P.; Chan, H.-K.; Chiou, H.; Ogawa, K.; Jones, M.D.; Adi, H. \& Buckton, G., (2009). Characterisation and aerosolisation of mannitol particles produced via confined liquid impinging jets. Int J Pharm, Vol. 367, pp. 51-57, ISSN: 0378-5173.

Tee, S.K.; Marriott, C.; Zeng, X.M. \& Martin, G.P., (2000). The use of different sugars as fine and coarse carriers for aerosolised salbutamol sulphate. Int J Pharm, Vol. 208, pp. 111123., ISSN: 0378-5173.

Telko, M.J. \& Hickey, A.J., (2005). Dry powder inhaler formulation. Resp Care, Vol. 50, No. pp. 1209-1227, ISSN: 0020-1324.

The Copley Scientific Limited, (2010). Quality Solutions for Inhaler Testing, inhaler testing equipment brochure, edition 2010.

Timsina, M.P.; Martin, G.P.; Marriott, C.; Ganderton, D. \& Yianneskis, M., (1994). Drug delivery to the respiratory tract using dry powder inhalers. Int J Pharm, Vol. 101, No. 12, pp. 1-13, ISSN: 0378-5173.

Todo, H.; Okamoto, H.; Iida, K. \& Danjo, K., (2001). Effect of additives on insulin absorption from intratracheally administered dry powders in rats. Int J Pharm, Vol. 220, pp. 101110, ISSN: 0378-5173.

Traini, D.; Young, P.M.; Jones, M.; Edge, S. \& Price, R., (2006). Comparative study of erythritol and lactose monohydrate as carriers for inhalation: Atomic force microscopy and in vitro correlation. Eur J Pharm Sci, Vol. 27, No. 2, pp. 243-251, ISSN: 0928-0987.

Ungaro, F.; d'Emmanuele di Villa Bianca, R.; Giovino, C.; Miro, A.; Sorrentino, R.; Quaglia, F. \& La Rotonda, M.I., (2009). Insulin-loaded PLGA/cyclodextrin large porous particles with improved aerosolization properties: in vivo deposition and hypoglycaemic activity after delivery to rat lungs. J Control Release, Vol. 135, No. 1, pp. 25-34, ISSN: 0168-3659.

Ungaro, F.; Giovino, C.; Coletta, C.; Sorrentino, R.; Miro, A. \& Quaglia, F., (2010). Engineering gas-foamed large porous particles for efficient local delivery of macromolecules to the lung. Eur J Pharm Sci, Vol. 41, pp. 60-70, ISSN: 0928-0987.

Ward, G.H. \& Schultz, R.K., (1994). Process-induced crystallinity changes of albuterol sulphate and its effect on powder physical stability. Pharm Res, Vol. 12, pp. 773-779, ISSN: 0724-8741.

Ward, G.H. \& Schultz, R.K., (1995). Processed-induced crystallinity changes in albuterol sulphate and its effect on powder physical stability. Pharm Res, Vol. 12, pp. 773-779, ISSN: 0724-8741.

Wolff, R.K. \& Dorato, M.A., (1993). Toxicologic testing of inhaled pharmaceutical aerosols. Crit Rev Toxicol, Vol. 23 pp.343-369, 
Yang, Y.; Bajaj, N.; Xu, P.; Ohn, K.; Tsifansky, M.D. \& Yeo, Y., (2009). Development of highly porous large PLGA microparticles for pulmonary drug delivery. Biomaterials, Vol. 30, pp. 1947-1953, ISSN: 0142-9612.

Young, P.; Cocconi, D.; Colombo, P.; Bettini, R.; Price, R.; Steele, D. \& Tobyn, M., (2002). Characterization of a surface modified dry powder inhalation carrier prepared by “particle smoothing". J Pharm Pharmacol, Vol. 54, No. 10, pp. 1339-1344, ISSN: 2042-7158.

Young, P.M.; Cocconi, D.; Colombo, P.; Bettini, R.; Price, R.; Steele, D.F. \& Tobyn, M.J., (2002). Characterization of a surface modified dry powder inhalation carrier prepared by "particle smoothing". J Pharm Pharmacol, Vol. 54, pp. 1339-1344, ISSN: 0022-3573.

Young, P.M.; Kwok, P.; Adi, H.; Chan, H.-K. \& Traini, D., (2009 ). Lactose composite carriers for respiratory delivery. Pharm Res, Vol. 26, No. 4, pp. 802-810, ISSN: 0724-8741.

Young, P.M. \& Price, R., (2004). The influence of humidity on the aerolisation of micronised and SEDS produced salbutamol sulphate. , . Eur J Pharm Sci, Vol. 22, pp. 235-240, ISSN: 0928-0987.

Young, P.M.; Sung, A.; Traini, D.; Kwok, P.; Chiou, H. \& Chan, H.K., (2007). Influence of humidity on the electrostatic charge and aerosol performance of dry powder inhaler carrier based systems. Pharm Res, Vol. 24, No. 5, pp. 963-970, ISSN: 0724-8741.

Zeng, X.M.; MacRitchie, H.B.; Marriott, C. \& Martin, G.P., (2007). Humidity-induced changes of the aerodynamic properties of dry powder aerosol formulations containing different carriers. Int J Pharm, Vol. 333, No. 1, pp. 45-55, ISSN: 0378-5173.

Zeng, X.M.; Martin, G.P.; Marriott, C. \& Pritchard, J., (2000). The effects of carrier size and morphology on the dispersion of salbutamol sulphate after aerosolization at different flow rates. J Pharm Pharmacol, Vol. 52, No. 10, pp. 1211-1221, ISSN: 0022-3573.

Zeng, X.M.; Martin, G.P.; Marriott, C. \& Pritchard, J., (2000). The influence of carrier morphology on drug delivery by dry powder inhalers. Int J Pharm, Vol. 200 pp. 93-106, ISSN: 0378-5173.

Zeng, X.M.; Martin, G.P.; Marriott, C. \& Pritchard, J., (2001). Lactose as a carrier in dry powder formulations: the influence of surface characteristics on drug delivery. J Pharm Sci, Vol. 90, No. 9, pp. 1424-1434, ISSN: 1520-6017.

Zeng, X.M.; Martin, G.P.; Marriott, C. \& Pritchard, J., (2001). The use of lactose recrystallised from carbopol gels as a carrier for aerosolised salbutamol sulphate. Eur J Pharm Biopharm Vol. 51, No. 1, pp. 55-62, ISSN: 0939-6411.

Zeng, X.M.; Martin, G.P.; Marriott , C. \& Pritchrd, J., (2000). The Influence of crystallization conditions on the morphology of lactose intended for use as a carrier for dry powder aerosols. J Pharm Pharmacol, Vol. 52, pp. 633-643, ISSN: 0022-3573.

Zeng, X.M.; Martin, G.P.; Tee, S.K. \& Marriott, C., (1998). The role of fine particle lactose on the dispersion and deaggregation of salbutamol sulphate in an air stream in vitro. Int $J$ Pharm, Vol. 176, No. 1, pp. 99-110, ISSN: 0378-5173.

Zeng, X.M.; Pandhal, K.H. \& Martin, G.P., (2000). The influence of lactose carrier on the content homogeneity and dispersibility of beclomethasone dipropionate from dry powder aerosols. Int J Pharm, Vol. 197, pp. 41-52, ISSN: 0378-5173. 
Zhou, Q.T. \& Morton, D.A.V., (2011). Drug-lactose binding aspects in adhesive mixtures: controlling performance in dry powder Inhaler formulations by altering lactose carrier surfaces. Adv Drug Deliv Rev,Vol.64 , pp. 275-284 ISSN: 0169-409X. 